\title{
UN EPICEDIO LATINO AL DUQUE DE ALBURQUERQUE.
}

\section{LUIS CHARLO BREA (1) Universidad de Cádiz}

\section{Introducción (2).}

«Entre los artículos del periódico de Londres, que indignamente se apellida el Español, hay uno que por creerle digno de nuestros lectores, y persuadidos de que no todos leen dicho periódico, (en lo que no pierden mucho) le insertamos original y traducido: pues siempre constantes en no exigir de nuestros lectores que sepan latín; sobre ser habas contadas los latines del Conciso (3), siempre irán con su traducción al canto».

El artículo del periódico londinense es, en realidad, una «inscripción para el sepulcro del Duque de Alburqueque» escrita en hexámetros latinos por Sir John Hookham Frere y traducida al castellano por José Blanco (White). Sánchez-Barbero (4) insertó original y traducción en El Conciso del lunes 6 de mayo de 1811 y la traducción fue reproducida en la biografía que del Duque de Alburqueque realizaron Francisco J. de Moya y Jiménez y Celestino Rey Joly (5).

En el presente trabajo, tras referirnos someramente a los personajes (autor, traductor y homenajeado), reproduciremos la poesía latina y la traducción de Blanco, estudiaremos los hexámetros latinos desde distintos puntos de vista y ofreceremos nuestra propia traducción del texto latino.

Antes, sin embargo, me parece oportuno dejar constancia del juicio crítico que la redacción de El Conciso hizo tanto de la poesía latina como de su traducción:

«Mucho honor hacen a Hockam sus versos latinos, y no hay expresiones en que elogiarlos dignamente; ora se miren por el lado de la soltura, pureza y armonía; ora se noten los rasgos de valentía y delicadeza que caracterizan al héroe; los sentimientos que excitan; el gusto que en ellos reyna... Se me figura oir a Arístides (6), quien al salir desterrado de su patria suplicó a los dioses, que nunca los Atenienses echasen de menos su falta. ¡Qué lástima que no fuera menos duro y pesado el verso $5^{\circ}$; más animado y sonoro el $9^{\circ}$; más poético el $11^{\circ}$ !

Por lo que hace a la traducción, si bien carece de contra-sentidos, no expresa todo el fuego del original: la pésima elección de los versos pareados fuerza alguna vez al Señor Blanco a interpretar más bien que a traducir. De ahí la más que moderada extensión; de ésta la debilidad y monotonía con que presenta las ideas, resultando de todo la separación de los movimientos que se suceden rápidamente en la fantasía del poeta latino. Más feliz fue este traductor 
en los versos originales con que tan vilmente aduló a Godoy; y lo es acaso en su prosáico periódico en que denigra, desune y desgarra a su patria, porque no sació su ambición; teniendo la avilantez de insultarla con apedillarse (lo que no es) el Español».

\section{Los personajes.}

a) El autor del poema latino.

Nacido en Londres en 1769, se educó John Hookham Frere en Eton y Cambridge. En ambas instituciones tuvo como condiscípulo a George Canning, futuro Secretario de Estado para Asuntos extranjeros, a quien siempre le unió una firme fidelidad política y una fuerte amistad personal.

Colaboró, junto con Canning, en el semanario de orientación política conservadora The Anti-Jacobin, distinguiéndose Frere por graciosas parodias propagandistas de la mentalidad tory y que publicaba bajo el seudónimo de William and Robert Whistlecraft.

Miembro del Foreing Office, donde llegó a ser Subsecretario de Estado para Asuntos extranjeros, fue enviado en 1800 a Lisboa como ministro plenipotenciario y posteriormente a Madrid en dos ocasiones, siendo en ambas destituido: la primera por impedir la alianza francoespañola, la segunda por errores políticos.

Retirado de la vida política a Malta, donde murió en 1841, se dedicó de pleno a su actividad humanística, donde se le recuerda fundamentalmente, además de por sus intentos de reintroducir en la poesía inglesa la «ottava rima» italiana, por sus trabajos sobre Teócrito y por sus traducciones de Aristófanes.

Entre sus publicaciones destacan los poemas The Loves of the Triangles y The Monks and Giants, un fingido poema heróico en «ottava rima»; la colección de documentos Theocritus Restitutus y, en colaboración con Canning, Needy Knif-Grinder.

b) El traductor.

Mucho más conocido (7) entre nosotros que el autor del poema, nos limitamos a exponer aquellas facetas de su vida que expliquen la reacción, palabras y juicio crítico del periódico gaditano.

Nació José $\mathrm{M}^{\mathrm{a}}$ Blanco y Crespo (Blanco- White) en Sevilla el 14 de julio de 1775, hijo de una andaluza y de un mercader irlandés cuyo apellido primero tradujo al castellano y recuperó después. Ordenado sacerdote, fue Canónigo primero en Cádiz y luego en Sevilla. Se convirtió después al anglicanismo y aún al unitarismo. Murió el 20 de mayo de 1841 en Liverpool. 
El 23 de febrero de 1810, huyendo de los ejércitos franceses, zarpó de la bahía de Cádiz en el Lord Howard camino de Inglaterra, donde intimó con Ricardo Wellesley. A instancias de éste funda El Español, periódico que propugnaba una franca alianza con Inglaterra en contra de las tropas napoleónicas, pero que vió con simpatía los intentos de independencia de las colonias americanas: un primer motivo de animadversión por parte española.

Otro motivo fue la publicación por parte de Blanco de un escrito del Duque de Alburquerque, donde se quejaba de las ofensas recibidas por el gobierno de Cádiz. Blanco publicó el escrito corrigiendo el estilo, y la Junta de Cádiz, notando la pericia del estilo, atribuyó a Blanco, que intentó una defensa a ultranza, la redacción.

La Junta terminó por prohibir la publicación del periódico de Blanco en España y sus colonias y aún se fundó un El Anti-Español, con la única finalidad de atacar a Blanco-White.

Son muchas las obras de Blanco-White, que realizó una notable labor como enlace de la poesía anglosajona con la española. Entre sus escritos en español destacamos Luisa de Bustamante o la Huérfana española en Inglaterra, publicada en la Revista de Ciencias, Literatura y Arte de Sevilla; entre sus obras inglesas de asunto español: Vargas. A tale of Spain,London 1822, en tres tomos, y, con el seudónimo de don Leocadio Doblado, Letters from Spain, London 1822; y entre sus obras inglesas el soneto Mysterious night.

c) El Duque de Alburquerque.

Don José $\mathrm{M}^{\mathrm{a}}$ de la Cueva y de la Cerda, XIV Duque de Alburquerque y $\mathrm{V}$ Marqués de la Mina, nació en Madrid a finales de 1775. A los 17 años de edad empezó a servir en el Ejército como Capitán agregado al Regimiento de Caballería Dragones de la Reina.

Durante la Guerra de la Independencia y estando al mando del ejército de Extremadura fue requerido por la Junta Suprema de Sevilla ante la proximidad de las tropas napoleónicas. No pudo llegar a Sevilla, y de acuerdo con dicha Junta, se adelantó a las fuerzas francesas y acudió presuroso en auxilio de la isla de León. El 28 de febrero de 1810 fue nombrado Gobernador Militar y Político de Cádiz, Capitán general de la provincia y costas de Andalucía y General en Jefe del Ejército de operaciones. Al día siguiente se entrevistó por primera vez con Ricardo Wellesley, a la sazón Ministro Plenipotenciario de Inglaterra.

Las distintas medidas tomadas por Alburquerque para la mejor defensa de la ciudad y mejora de las condiciones de su propio ejército, quejas que el general hacía frecuentemente públicas, no aceptadas de buen grado por la Junta de Cádiz, enfriaron unas hasta entonces muy cordiales relaciones. La publicación, a pesar de los buenos oficios de Wellesley, de distintos y contradictorios 
manifiestos, unos de Alburquerque, otros de la Junta, terminó por dividir al pueblo, que tomó abiertamente parte por la Junta.

Alburquerque fue entonces nombrado Embajador extraordinario en Londres («cargo pedido por el Duque en vista de la imposibilidad de continuar en Cádiz, donde se había hecho en extremo impopular», según palabras de Wellesley al Foreing Office (8), donde fue cordialmente recibido y agasajado, pues «la afición que tenía a cuanto era inglés, y su amistad con Frere y con Lord Wellesley, con Welligton y con Holland, hacíanle desde luego persona gratísima, y hubiera servido para facilitar su misión diplomática en Inglaterra, si hubiese tenido ésta otro objeto que el de apartarlo de Cádiz» (8).

La preocupación constante que, aún en Inglaterra, tenía por contestar a las réplicas de la Junta de Cádiz le llevó a pedirle a Blanco-White que le redactara un Manifiesto en el que defendía su propio honor militar y el de su ejército. Se le comunicó por parte de la Regencia que reconocía su celo y que regresara a la mayor brevedad posible, pues se le confiaba el mando del Ejército de Galicia; pero la Junta gaditana lo tachó de calumniador, traidor y de enemigo de la Patria.

Sin ver realizados sus deseos, falleció en Londres el 18 de febrero de 1811, a los 35 años recién cumplidos. Inglaterra lo homenajeó pública y privadamente. Entre estos homenajes el epicedio que comentamos.

El Duque de Alburquerque reposa hoy en la Iglesia del Carmen de la capital gaditana. 


\section{El epicedio latino}

Inscripción para el sepulcro del Duque de Alburquerque por el muy Honorable Juan Hockam Frere.

Impiger, impauidus, spes maxima gentis Iberae,

Mente rapax acerque manu bellator, auita

Institui monumenta nouis attollere factis.

Fortuna comite et uirtute duce omnia gessi;

Nulla in re nec spe mea sors incepta fefellit. 5

Gadibus auxilium tetuli patriamque labantem

Sustentaui: haec meta meis fuit ultima factis.

Quippe iras hominum meritis superare nequiui,

5 incepta scripsi : incaepta Conciso

1 Val. Fl. 1, 242 ....spes maxima... 2 Verg. Aen. 11, 552-553 ...manu.../ bellator... 2-3 Ov. met. 13, 524 ...monumentis...auitis! fast. 2, 265 ...monimenta...facti 3 Prop. 3, 3, 26 ...noua...facta... Ov. met. 8, 96 ...noui...facti Sil. 13,635 ...*attollere factis* 4 Luc. 5, 510 ...fortuna comes... 9,882 ...ducis uirtus... 2,41 ...fortuna ducum 10,376 ...fortuna ducis... 4,342 ...gerit omnia... Ov. Pont. 1, 9, 16 ...Fortunae...comes Hor. carm. 4, 15, 29 uirtute...duces 5 Verg. Aen. 4, 638 ...*incepta paraui* Aen. 7, 259 ...*incepta secundent* Ov. Pont. 4, 14, 47 ..*mea sors*... Val. Fla. 3, 490 ...inceptis...fallere 6 Verg. Aen. 2, 344 ...*auxilium*...ferebat Ov.epist. 5, 154 ...*auxilium*...ferre... fast. 2, 470 ...auxilium ferte... 7 Verg. Aen. 3, 714 ...haec meta... Ov. met. 4, 632 ...*fuit ultima*... 8 Ov. trist. 3, 5, 41 ...hominum...iras Sil. 15,94*Quippe*...ira Stat. Theb. 1,623 ...nequit iram explere... 
Hic procul a patria uitae datus est mihi finis,

Sed non laudis item. Gliscit noua fama sepulto, 10

Anglorum quod testantur proceres populusque,

Magno funus honore secuti maestitiaque

Unanimes. Aeterna, pater, sint foedera, faxis,

Quae pepigi. Nec me nimium mea patria adempto

Indigeat nec plus aequo desideret unquam.

Sint fortes alii et felices, qui mea possint

Facta sequi semperque benignis ciuibus uti.

14 adempto scripsi : ademto Conciso

9 Verg. ecl. 10, 46 ...*procul a patria*... Ov. met. 3, 251 ...finita...uita trist. 3, 7, 49 ...uitam mihi finiat... $I b .312$...finem uitae... Pont. ...mihi finis erit 10 Ov. epist. 4, 27 ...noua...famae epist. 19, 108 ...fama...noua epist. 7, 92 ...fama sepulta... Pont 1, 5,85 ...fama sepulta... Sil. 6,63 ...fama gliscente... 11 Verg. Aen. 3, 58 ...populi...proceres... Ov. trist. 3, 6, 5 ...populo testatus... Val. Fla. 5, 405 ...proceres...populosque... 12 Luc. 5, 763 Magne...funus... 9, 29 ....Magni funera... Ov. Pont. 1,9,51 ...magni funus honoris Hor. serm. 1,6, 43 ...funera magna... Stat. silu. 5, 3, 106 ...magni funus... Prop. 2, 6, 11 ...sequitur...honores Verg. ecl. 4, 48 ...magnos honores Ov. fast. 3, 122 ...magno...honore... Val. Flac. 4, 76 ...magno honore 13 Catull. 109, 6 aeternum...foedus... Verg. georg. 1, 60 ...aeternaque foedera Aen. 11, 356 ...aeterno foedere... Aen. 12, 191 ...aeterna in foedera Aen. 8, 540 ...pater...*foedera*... Hor. serm. 2, 3, 38 ...*faxis* 14 Stat. Theb. 10, 764 *Quae pepigi*... Ov. epist. 3, 214 ...mea patria... epist. 9, $166 \quad \ldots$...patria et patriae...adempte... trist. $2,1,202 \quad$...patria...adempta... Pont. 1, 2, 14 ...patria...adempta... 15 Ov. epist. 12, 11 ...plus aequo... trist. 1, 5, 45-46 ...desiderat.../plus... Hort. serm. 1, 3, 52 Plus aequo... epist. 1, 2, 29 ...plus aequo... 16 Catull. 68, 155 Sitis felices... Tib. 3, 6, 30 Sis felix... Prop. 1, 7,3 ...sim felix... Ov. met. 7,620 ...sint...felicia... met. 14, 480-481 ...felices sunt illi.../quos... Pont. felices illi qui... Ciris 2, 28 felices qui... 16-17 Verg. Aen. 12,775-776 ...sequi quem.../non poterat Luc. 1,372 ...sequi...posse... Ov. epist. 12,136 ...qui me sequitur semper... Val. Flac. 8, 364 ...potest...sequi Stat. silv. 3 «pr» 14 ...sequi non poteram... Verg. Aen. 4, 109 ...factum...sequatur Ov. epist. 14, 16 ...facta...sequi epist. 16, 327 ...sequar...factum... Hort. carm. 4, 11, 29 ...semper...sequare Luc. 9, 250 ...semper sequeris... 


\section{Comentario métrico.}

No puede ser muy significativo - tenemos sólo diecisiete versos - el resultado del estudio métrico del poema. Con el fin, no obstante, de acercarnos un poco a las cualidades versificadoras de este autor inglés de los inicios del siglo XIX, lo hemos llevado a cabo.

a) Cuatro primeros pies.

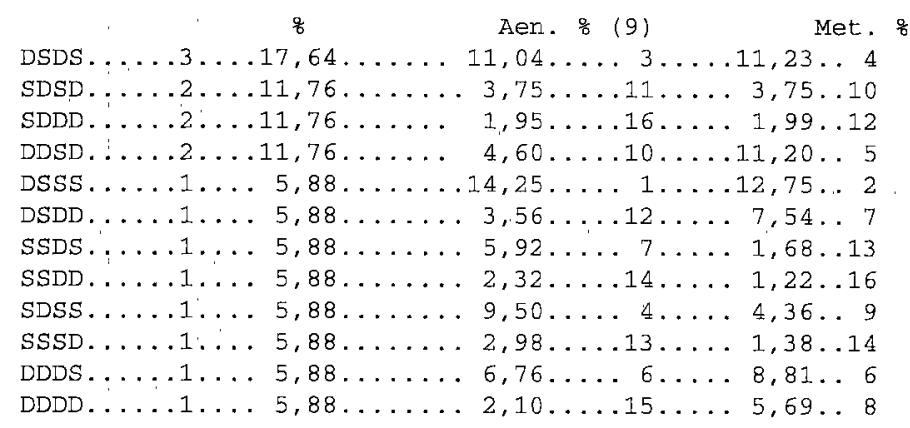

De las dieciséis combinaciones posibles, nuestro autor utiliza doce en diecisiete versos, entre ellas todas las menos utilizadas por Virgilio y muchas de las menos utilizadas por Ovidio. No utiliza, en cambio, la segunda de Virgilio ni la primera de Ovidio. No se acerca, pues, en este punto, a nuestros autores clásicos.

b) Cesuras y monosílabos ante ellas.

De las doce cesuras pentemímeras, encontramos dos (vv. 2 y 17) antes de enclítica (10) y otra dos ( vv. 5 y 14) precedidas por monosílabos precedidos a su vez por otro. En los versos 3, 7 y 13 encontramos Triple A y Triple B (11) en el v. 11. Todo ello en perfecta consonancia con el uso clásico (12). No hay, sin embargo, cesura alguna en el verso 12.

c) Elisiones.

Las siete contabilizadas: v. 4 en 3 A y 5 A, v. 5 y v. 8 en 1T, v. 7 en $2 T$ y v. 14 en $5 \mathrm{~T}$, suponen un porcentaje muy elevado (13). Nótese, por otro lado, que de estas siete elisiones sólo una se encuentra en lugar tradicional, la del v. 8, y una, la del v. 14, no se adapta a lo señalado por Mueller (14).

d) Estructura silábica y finales de hexámetro: el monosílabo final. 
Sólo dos versos, y son muchos en un poema de diecisiete, se apartan de lo que suele ser norma: si nada aceptable es el final del v. $11,1+4$, mucho menos lo es el del v. 12: maestitiaque. Recuérdese que no encontrábamos cesura en este verso 12 y nótese ahora el encabalgamiento sintáctico: maestitiaque unanimes, con posible elisión entre la vocal final del verso que nos ocupa con la inicial del verso siguiente. Todo parece indicar que nos encontramos con un alargamiento métrico del verso 12 con pausa sintáctica tras secuti.

\section{Comentario de fuentes.}

Creo oportuno indicar, en primer lugar, los criterios que, por razones sobre todo de espacio, he seguido en la selección de fuentes: cuando un calco aparece en varias obras, sean del mismo sean de distinto autor, consigno únicamente la obra considerada más antigua. Damos siempre preferencia, no obstante, en nuestra estadística a la iunctura que encontramos en la misma sedes métrica, aunque el autor u obra sea más tardio. Un ejemplo lo explica mejor: encontramos mea sors tres veces en Ovidio (fast. 3, 477; trist. 3, 3, 29 y Pont. 4, $14,17)$; contabilizo sólo la cita de Pont. porque es anterior en el tiempo a la de trist. y, aunque más moderna que la de fast., se encuentra en el mismo lugar métrico. Otro ejemplo: Procul a patria utilizado en la misma sedes métrica por Virgilio anula estadísticamente las muchas veces que Ovidio utiliza, también en la misma sedes, este sintagma.

Los poetas que hemos rastreado son: Catulo, Propercio, Tibulo, Virgilio y el Appendix Vergiliana, Horacio, Lucano, Ovidio, Estacio, Valerio Flaco, Marcial y Silio Itálico. En Propercio 1, 3, 46 leemos illa fuit lacrimis ultima cura meis, muy afín, al menos conceptualmente, a nuestro v. 7; y en Cicerón, Fam. 10, 3, 2: Virtute duce, comite fortuna (15), que, por razones métricas, Frere adulteró en el cuarto verso. No hemos, sin embargo, anotado ambas expresiones en fuentes.

Son así 79 las iuncturae que hemos contabilizado, 6 de ellas en la misma sedes métrica. Fácilmente se observa que Virgilio con $14(17,72 \%)$ y Ovidio con $31(39,24 \%), 2$ y 2 en la misma sedes respectivamente, siguen siendo, el poema es de comienzos del siglo XIX, los autores más utilizados. Pero debemos resaltar la clara presencia de Silio Itálico en el v. 3 ...*attollere factis*, los cinco $(6,32 \%)$ calcos tomados de Valerio Flaco y los cuatro $(5,06 \%)$ de Estacio: todos ellos de la segunda mitad del siglo I d. C.

\section{Comentario estilístico.}

No puede menos de llamar la atención en un poema tan corto la utilización de tres perfectos reduplicados. Mucho más si tenemos en cuenta que en toda la poesía latina que hemos revisado no son frecuentes: las formas reduplicadas del tema de perfecto del verbo fero, que son ya en sí arcaísmos, sólo son utilizadas por Catulo y sólo en tres ocasiones (tetulit en 63, 47; tetuli en 63, 52; tetulisset 
en 66,35 ); cuarenta y una y catorce veces respectivamente, son usadas las de fallo y pango. Nunca los tres verbos en una misma composición poética.

Tampoco están muy documentadas en la poesía latina clásica las formas arcaicas del verbo facio. Horacio se sirve dos veces y una Silio Itálico del subjuntivo faxis; faxo aparece en catorce ocasiones: dos en Virgilio, Ovidio y Estacio; 4 en Valerio Flaco y en Silio Itálico. Añadamos, por último, que las formas todas del verbo glisco que usan los poetas latinos son sólo veinticinco.

A este vocabulario, selectivo y arcaico, se añade otra segunda característica: los múltiples encabalgamientos, que se suceden, con muy contadas excepciones, a partir del v. 5. Si exceptuamos los cinco primeros versos, apenas si encontramos «coincidencia de la frontera versal con la pausa sintáctica» (16). Encabalgamientos, todos ellos y en terminología del Dr. Holgado, abruptos incipientes (17), ya que el sintagma del verso encabalgante, si bien se quiebra bruscamente, no excede en ninguna ocasión la cesura pentemímera del encabalgado.

Es de notar también la abundancia de monosílabos que encontramos en el verso 5. La secuencia métrica que forman esos monosílabos, SSDS, confiere cierta lentitud a este verso que ya El Conciso tildara de duro y pesado por la frecuencia de espondeos. Espondeos que encontramos también, ahora SSSD, en otro verso, sin monosílabo alguno, criticado por el periódico como poco poético, y que a nosotros nos parece, sin embargo, lleno de majestuosidad y no exento de sensibilidad poética latina: nos estamos refiriendo al verso 11 , verso llamado a excitar en el lector hispano, y sobre todo gaditano, la comparación entre su propio comportamiento y el de los ingleses para con el duque de Alburquerque. Se vale para ello de procedimientos tan poéticos como la colocación de Anglorum y populus en lugar métrico privilegiado, como lugar métrico privilegiado, ante cesura, ocupa testantur, precisamente testantur, de enorme valor léxico; el fuerte hipérbaton entre la palabra inicial y final del verso, determinante y determinado sintáctico, incrementa el mérito poético, que se empaña, por otro lado, por su no acostumbrada estructura silábica final, como ya hemos comentado.

Verso 11, que, por la razones indicadas, nos parece fundamental en la estructura del poema. Como fundamental nos parece también el verso 6, y obsérvese las palabras situadas en zonas métricas claves, Gadibus...tetuli// patriam...suatentaui. Ambos versos parecen resumir el poema (gasté mi vida entre Cádiz y mi patria; son los ingleses quienes me honran) y, anunciar un final casi epigrámatico: que vengan otros tan valientes como yo, pero más felices al contar con el elogio de sus propios conciudadanos.

«Más animado y sonoro el verso el $9^{\circ}$ », decía el crítico del periódico gaditano. Una simple lectura del aparato de fuentes nos exime de todo comentario: el verso 9 está calcado en Virgilio, Ovidio y otros autores latinos clásicos. 


\section{La traducción de Blanco-White.}

Impertérrito, Activo, audaz, valiente Apoyo fue de la Española gente.

Nueva gloria a los timbres de mi cuna Me consiguió el valor y la fortuna Que, para mí sin ceño y sin mudanza,

Jamás frustó mi esfuerzo o mi esperanza.

La patria iba a espirar, quando mi mano

La conservó en el suelo gaditano.

Este el término fue de mi carrera;

Si generosidad, si honor pudiera

De algunos hombres amansar las iras,

No baxara tan pronto a do me miras.

Ausente aquí, lejano de mi España

Hallé fin a mi vida en tierra extraña;

Mas no a mi gloria. Hasta el sepulcro umbrío

Transciende el nuevo honor del nombre mío;

El nuevo honor que la nación inglesa

Tributa a mis cenizas en la huesa.

De próceres y pueblo rodeado,

De próceres y pueblo fui llorado.

Benigno Dios...! eternizad el lazo

De esta amistad que consagró mi brazo.

Mi brazo...! ;oh! nunca en la gloriosa guerra

Llore su falta mi adorada tierra.

Llóreme, sí; mas no con desconsuelo:

Názcanle otros valientes en su suelo,

Que imitando el ejemplo de mi vida

Disfruten gratitud no interrumpida.

Sin caer en los juicios peyorativos que Blanco-White recibía de $E l$ Conciso, sí tenemos que decir que el hispano-irlandés tradujo de oficio el poema latino. Se limitó a ponerlo en una serie monoestrófica de pareados endecasílabos, tipo de poema generalizado en el siglo XVIII, por influencia de la poesía francesa, y que todavía se cultivaba en el XIX.

\section{Nuestra propia traducción.}

Infatigable, impávido, esperanza la más grande del pueblo ibero, luchador de ágil mente y brazo fuerte, engrandecí con gestas nuevas viejas glorias: «con la virtud por guía y la fortuna por compañeras todo lo hice bien, y en nada, que comenzara o deseara, me defraudó mi ventura. Presté a Gades auxilio y a mi 
patria, cuando se derrumbaba, mantuve firme: tal fue la meta final de mis hazañas.

Porque no pude superar con méritos las iras de los hombres, aquí, lejos de mi patria, he visto el fin de mis días, pero no el de mis laudes. Ya sepultado, uno nuevo acrecienta mi honor, como atestiguan los próceres y el pueblo inglés, que, unánimes en su tristeza, me honraron con gran funeral.

Que sean, padre, haz, sempiternos, los lazos que establecí; que mi patria no necesite mi presencia ni jamás en exceso me añore. Que florezcan otros, valientes y felices, que continúen mis gestas y disfruten de agradecidos ciudadanos.

\section{NOTAS.}

* El presente trabajo está incluido en el Proyecto de Investigación PS93-0130 de la DGICYT.

(1) A José Luis Millán Chivite, amante de Cádiz, profesor de Historia Contemporánea, comentarios a una poesía latina, escrita a comienzos del siglo XIX y que hace referencia a Cádiz.

(2) Agradezco a Francisco Bravo Liñán haberme ofrecido sus datos sobre poesías latinas publicadas en la prensa gaditana.

(3) «Las publicaciones que surgen en la isla gaditana durante el período de las Cortes y Guerra de Independencia son muy numerosas. Entre 1810 y 1814 proliferan estas publicaciones, tanto en Cádiz como en San Fernando: $E l$ Telescopio político, La Triple alianza, El Robespierre español, El Conciso, El Redactor General, Gaceta de la Regencia, El tribuno del pueblo español, El telégrafo americano...

El Redactor General era para Ramón Solis el más interesante de cuantos se publicaran en la época. Recogía una selección de las opiniones de los demás periódicos con breves comentarios. Aparecían en él resúmenes de lo que opinaban periódicos <<serviles>> como El Censor General o El Diario de la tarde y también de <<liberales $>>$ con el Diario Mercantil o El Conciso, éste el primero en dar información directa de las sesiones de las Cortes. Colaboran en esos años en la prensa gaditana José María Lequerica, Martínez de la Rosa, Alcalá Galiano, Bartolomé José Gallardo, Vadillo, Quintana, Capmany, etc.» leemos en Ramos Santana, A. et alii, Prensa gaditana 1763-1936, Cádiz 1987, p. 9. Cf. et Solís, R., «La prensa» en El Cádiz de las Cortes: La vida en la ciudad en los años de 1810 a 1813, Sílex, Madrid 1987, pp. 319-348.

(4) Una breve biografía de este autor, con abundantes notas (una, la 112, hace alusión a la prensa gaditana del momento) e interesante bibliografía puede verse 
en Torres-Alcalá, A., VERBI GRATIA: Los escritores macarrónicos de España, Madrid 1984.

(5) Cf. Moya y Jiménez-Rey Joly, El ejército y la marina en las Cortes de Cádiz, Cádiz 1914, pp. 600-650.

(6) Arístides, hijo de Lisímaco, denominado El Justo, fue condenado al ostracismo a instancias de su enemigo personal y político Temístocles. Cuando salía de la ciudad, «levantó sus ojos al cielo y suplicó - súplica contraria a la que según parece hizo Aquiles - que ninguna crisis sobreviniera a los Atenienses que los obligara a acordarse de Arístides». Ante la inminente invasión de los Persas $\mathrm{y}$ antes de cumplir los preceptivos 10 años de destierro, fue urgentemente requerido por sus compatriotas. $C f$., al respecto y especialmente, Plut. Vita Aristidis, 7, 6.

(7) Un acercamiento (suficiente para los fines de este trabajo) a la vida y pensamiento de este autor puede verse en Méndez Bejarano, M., Vida y obras de D. José $M^{a}$ Blanco y Crespo, Madrid 1921.

(8) Moya y Jiménez-Rey Joly, o. c., pp. 622 y 624 respectivamente.

(9) Datos sacados de Pozuelo Calero, B., El Licenciado Francisco Pacheco. Sermones sobre la instauración de la libertad del espiritu y lírica amorosa, Cádiz-Sevilla 1993, p. 74, donde se explicita el tanto por ciento de utilización.

(10) Cf. Herrero Llorente, V. J., La lengua latina en su aspecto prosódico, Madrid 1971, pp. 171-172, y Mariner Bogorra, S., «Hacia una métrica estructural», E.S.E.L 1971, p. 319.

(11) Cf. Nougaret, L., Traité de Métrique latine classique, Paris 1963, pp. 34-35.

(12) Cf. Maestre Maestre, J. $\mathbf{M}^{\mathbf{a}}$., «Poesías varias» del alcañizano Domingo Andrés, Teruel 1987, p. LXI.

(13) Cf. Maestre Maestre, J. Mª, o. c., p. LX.

(14) Cf. Mueller, L., De re metrica poetarum Latinorum praeter Plautum et Terentium libri septem, Hildesheim 1967, p. 360.

(15) Herrero Llorente, V. J., en Diccionario de expresiones y frases latinas, Madrid $1985(=1980)$, p. 403, recoge estas palabras de Cicerón, que traduce como «con la virtud por guía y la fortuna por compañera».

(16) «El encabalgamiento, como es sabido, consiste en un desajuste, en una falta de coincidencia de la frontera versal con la pausa sintáctica, lo que da lugar a una dislocación o asimetría, a un conflicto entre metro y sintaxis», nos enseña 
Holgado, A., La frontera de verso en «La Farsalia» de Lucano. Estudio estilístico, Cádiz 1987, p. 32.

(17) Cf. Holgado. A., o. c., pp. 41-45, donde crea y explica toda esta terminología. 